Original Research Paper

\title{
Decalin Dissolving Method for Recover of Styrene -Butadiene Rubber from Scrap Tires
}

\author{
Aeppa M.T. Sultan and Fawzi Habeeb Jabrail \\ Polymer Research Lab., Department of Chemistry, College of Science, University of Mosul, Iraq
}

\author{
Article history \\ Received: 18-08-2019 \\ Revised: 10-09-2019 \\ Accepted: 11-10-2019 \\ Corresponding Author: \\ Fawzi Habeeb Jabrail \\ Polymer Research Lab., \\ Department of Chemistry, \\ College of Science, University \\ of Mosul, Iraq \\ Tel: +9647703336282 \\ E-mail: fawzidcy@yahoo.com
}

\begin{abstract}
Decalin, a hydrocarbon industrial solvent was used for the recovery of Styrene- Butadiene Rubber (SBR) from grind scrap truck tires using chemical dissolving method. The applied technique is easy, simple and depends on available materials. The method depends mainly on steeping the scrap tires grind into decalin at $50^{\circ} \mathrm{C}$ for one month. Then the process was followed by boiling of the formed thick black solution $\left(198^{\circ} \mathrm{C}\right)$ for two hours. The formed elastic rubber material will be reclaimed by precipitation in methanol. The recovered rubber was characterized using FTIR spectroscopy and XRD analyses. The pattern of the recovered material shows broad maxima of SBR with the absence of XRD peaks of carbon black and almost all the other tire manufacturing additives. The thermal characteristics of the reclaimed rubber have been investigated by TGA, DTG and DSC analyses and were found to be close to those of thermal properties of SBR polymer. The SEM image has shown non-crystalline morphological surface of the recovered rubber with cohesive elastomeric properties.
\end{abstract}

Keywords: SBR Reclaims, Decalin Dissolving Method, Scrap Tires, Steeping Method, Recycling

\section{Introduction}

The world consumes 4.5 million tons of tires, in addition to billions of tires of different types are to be disposed of in the USA. This huge amount of scrap tires is a big concern as ecological pollution problem (Czajczynska et al., 2017). While it could be used as an alternative source of energy if this scrap is transformed into useful material. This scrap consists of about $60-65 \%$ rubber (Martinez et al., 2013) and the rest are different additives and fillers. Therefore, isolation of the rubber from the other additives should be a valuable way to obtain a useful material which could be processed and reused in several industrial procedures.

Several process have been developed for tires recycling. Pyrolysis of the scrap tires under vacuum was extensively used to produce tire-derived oils that may be used as fuel or added to conventional fuels in order to reduce the dependence on the limited fossil oils (Murugan et al., 2009). However, most methods of rubber recovery from the scrap were found unsatisfactory since many treatments lead to ecological problems and insufficient pure rubber recovery (Umeki et al., 2016). In many countries inappropriate disposal of the scrap tires is done by incineration in the open fields, which causes dramatic pollution problem.
Vehicle tires are made of rubber after vulcanization with sulfur to render it crosslinked and after adding several additives, like fillers, steel wires, plasticizers, extenders accelerators, curing agents and others in order to improve their mechanical, thermal and physical properties. This complicated structure makes rubber recovery quite a difficult task (Mastral et al., 1999; 2000).

Decalin, is an industrial hydrocarbon solvent used for dissolving resins and can be blended with other hydrocarbons solvents to be used as high density rocket ramjet and turbojet fuels (Bryant and Burdette, 1978 US Patent 4,099,931). Decalin was used in thermal degradation of HDPE polymer (Aguado et al., 2006) where it could facilitate the degradation process and had a significant effect on the product distribution. Decalin participates in the degradation mechanism and effects the degradation time and temperature significantly (Aguado et al., 2007). Decalin has hydrogen donating ability as solvent has been investigated as a method for the feedstock recycling of plastic wastes.

Decalin a bicyclic saturated hydrocarbon was used in the present work as solvent for reclaiming the rubber from scrap tires. Decalin has the ability to penetrate into the tire materials, swell them and finally extract the rubber out. The work includes treatment of the scrap 
tires with decalin and the extracted rubber was studied carefully using spectral, XRD, thermal analysis. SEM images were used to see any differences between pristine tire and its recovered rubber.

\section{Experimental}

\section{Materials}

Truck scrap tires were supplied from the local market. The tire samples were prepared by cutting into pieces, cleaned and grinded. Decalin from BDH Chemical Company, UK was used without further purification. Methanol from Fluka, Switzerland was used as received.

\section{Decalin Steep of Scrap Tire for a Long Time}

$10 \mathrm{~g}$ of grinded scrap tire were steeped in $100 \mathrm{~mL}$ of decalin in a conical flask and the flask was heated on water bath at $50^{\circ} \mathrm{C}$ for 30 days.

\section{Rubber Recovery Procedure}

After 30 days steeping the solution turned into black color with a thick texture. This black thick solution was then transferred into $250 \mathrm{~mL}$ round bottom flask connected to condenser and was refluxed for about $3 \mathrm{~h}$ at the boiling point of decalin $\left(198^{\circ} \mathrm{C}\right)$ using mantel and in presence of boiling chips. The solution, was left to cool. The separation of undissolved suspended materials, which are mainly carbon black, was carried out using ultra centrifuge at $13000 \mathrm{rps}$. Methanol (43\% v/v) was added for precipitation separation of rubber however, since methanol is not miscible with decalin because of their polarities, the mixture was spread in Petri dish inside an oven at $30^{\circ} \mathrm{C}$ until dried. A thick white layer with rubbery texture was collected. The separated carbon black could be used after washing with methanol.

\section{Characterization of Recovered Rubber and Pristine Tire Samples}

\section{FTIR Spectrophotometry}

FTIR spectra were recorded on a Fourier-Transform Infrared spectrophotometer model S8400 from Shimadzu Company, Japan. The spectra were measured in the spectral range $400-4000 \mathrm{~cm}^{-1}$.

\section{$X$-Ray Diffraction (XRD) Analysis}

X-ray diffraction measurements of the recovered rubber and a pristine sample were recorded at a scan of 1 min $^{-1}$ using XRD -600/Shimadzu/Japan) using copper Indium $(0.9 / 0.1) 100 \%$ radiation target and nickel filter at a current $20 \mu \mathrm{A}$ under a voltage of $35 \mathrm{kv}$.

\section{Thermal Measurements}

Thermogravimetric (TG), Differential Thermogravimetric (DTG) analyses and Differential
Scanning Calorimetry (DSC) of only the recovered rubber sample was measured using TG instrumental type METTLER TOLEDO (Switzerland) micro and ultra micro balances, under nitrogen atmosphere at a heating rate of $10^{\circ} \mathrm{C} / \mathrm{min}$ in the temperature range of $25-600^{\circ} \mathrm{C}$.

\section{Scanning Electron Microscopy}

SEM images of the recovered rubber and the untreated scrap tire samples were mounted on aluminum studs using double adhesive taps and coated under vacuum by exposing to a gold ion beam sputter. The type of SEM instrument used was TESCAN-VEG/USA.

\section{Proton Nuclear Magnetic Resonance ( $\left.{ }^{1} H N M R\right)$ Measurement}

${ }^{1}$ HNMR of rubber sample of the recycled material of scrap tire extracted by decalin has been investigated and its structure was analyzed by 1HNMR using the instrument Bruker Biospin $\mathrm{GmbH}$ of $400 \mathrm{MHz}$ spectrometer frequency. Where the samples dissolved in $\mathrm{CDCl}_{3}$ solvent and measured at room temperature.

\section{Results and Discussion}

Most recycling processes of the scrap tires depends on either incineration for energy reclaims; pyrolysis to oil for an alternative fuel for diesel engines; crumbed the tires for flooring indoor arena, or the tires were recycled by shredding and filled cement composition for certain infrastructural applications. In general, most treatments are not directed for reclaiming rubber from the scrap tires. The present work concentrates on recovery of rubber from scrap tires in a form that can be reused again.

\section{Characterization of the Recovered Rubber}

The pristine scrap tire sample before treatments has been characterized and compered with the recovered rubber.

\section{FTIR Study}

The absorption frequencies of scrap and recovered rubber samples are including in Table 1 and Fig.1.

In general, the spectra show that the sample mainly consists of hydrocarbon groups, The band at $3080 \mathrm{~cm}^{-1}$ represents $\gamma(\mathrm{C}-\mathrm{H})_{\text {str }}$ of aromatic ring and $\gamma\left(\mathrm{CH}_{2}\right)_{\text {str }}$ aliphatic. The absorption frequency at $1452 \mathrm{~cm}^{-1}$ represents $\gamma(\mathrm{C}-\mathrm{H})_{\text {def }}$ and $\gamma(\mathrm{C}=\mathrm{C})_{\text {str }}$ of aromatic ring, beside the peak at $1069 \mathrm{~cm}^{-1}$ of $\gamma(\mathrm{C}-\mathrm{H})$ in the plane, representing those for the spectrum of polystyrene (Leon-Bermudez and Salazar, 2008). In addition, the absorption frequencies at $1630 \mathrm{~cm}^{-1}$ and $1660 \mathrm{~cm}^{-1}$ belong to $\gamma(\mathrm{C}=\mathrm{C})$ of the aliphatic chain of butadiene (Munteanu and Vasile, 2005). 
Table 1: FTIR wave numbers of the characteristic bands of pristine scrap tire and recovered rubber samples

\begin{tabular}{|c|c|c|c|c|c|c|c|c|c|}
\hline \multirow[b]{2}{*}{ Examined sample } & \multicolumn{9}{|c|}{ Wave number characteristic bands $\left(\mathrm{cm}^{-1}\right)$} \\
\hline & $\begin{array}{l}\gamma(\mathrm{C}-\mathrm{H})_{\text {str }} \\
\text { aromatic ring }\end{array}$ & $\begin{array}{l}\gamma(\mathrm{C}-\mathrm{H})_{\text {str }} \\
\text { aliphatic }\end{array}$ & $\begin{array}{l}\gamma(\mathrm{C}=\mathrm{C})_{\mathrm{str}} \\
\text { aromatic ring }\end{array}$ & $\begin{array}{l}\gamma(\mathrm{C}=\mathrm{C})_{\text {str }} \\
\text { aliphatic }\end{array}$ & $\begin{array}{l}\gamma(\mathrm{C}-\mathrm{H})_{\text {def }} \\
(\mathrm{C}=\mathrm{C}) \\
\text { aromatic }\end{array}$ & $\begin{array}{l}\gamma(\mathrm{C}-\mathrm{H}) \\
\text { in the plane }\end{array}$ & $\begin{array}{l}\gamma(\mathrm{C}-\mathrm{H})_{\text {st }} \\
\text { aliphatic }\end{array}$ & $\begin{array}{l}\gamma(\mathrm{C}-\mathrm{H}) \\
\text { wag }\end{array}$ & $\begin{array}{l}\gamma(\mathrm{C}-\mathrm{H}) \\
\text { twist }\end{array}$ \\
\hline Pristine scrap tire & 3080 & $\begin{array}{l}2843 \\
2920\end{array}$ & 1731 & $\begin{array}{l}1630 \\
1660\end{array}$ & 1452 & 1069 & 1196 & 910 & 520 \\
\hline Recovered rubber & $\begin{array}{l}\gamma(\mathrm{C}-\mathrm{H}) \text { str } \\
\text { alkenyl } \\
3024 \\
3059\end{array}$ & $\begin{array}{l}\gamma(\mathrm{C}-\mathrm{H}) \mathrm{str} \\
\text { alkyl } \\
2849 \\
2924\end{array}$ & $\begin{array}{l}\gamma(\mathrm{C}=\mathrm{C}) \\
\text { alkene } \\
1601 \\
1678\end{array}$ & $\begin{array}{l}\gamma \\
(\mathrm{CH} 2)_{\text {def }} \\
1493\end{array}$ & $\begin{array}{l}\gamma(\mathrm{C}=\mathrm{C}) \\
\text { aromatic ring } \\
1448\end{array}$ & $\begin{array}{l}\gamma \\
(\mathrm{CH}=\mathrm{CH}) \mathrm{str} \\
1373\end{array}$ & $\begin{array}{l}\gamma(\mathrm{C}-\mathrm{H}) \\
\text { in the plane } \\
1070\end{array}$ & $\begin{array}{l}\gamma(\mathrm{C}-\mathrm{H}) \\
\text { alkenyl } \\
758 \\
903 \\
960\end{array}$ & \\
\hline
\end{tabular}

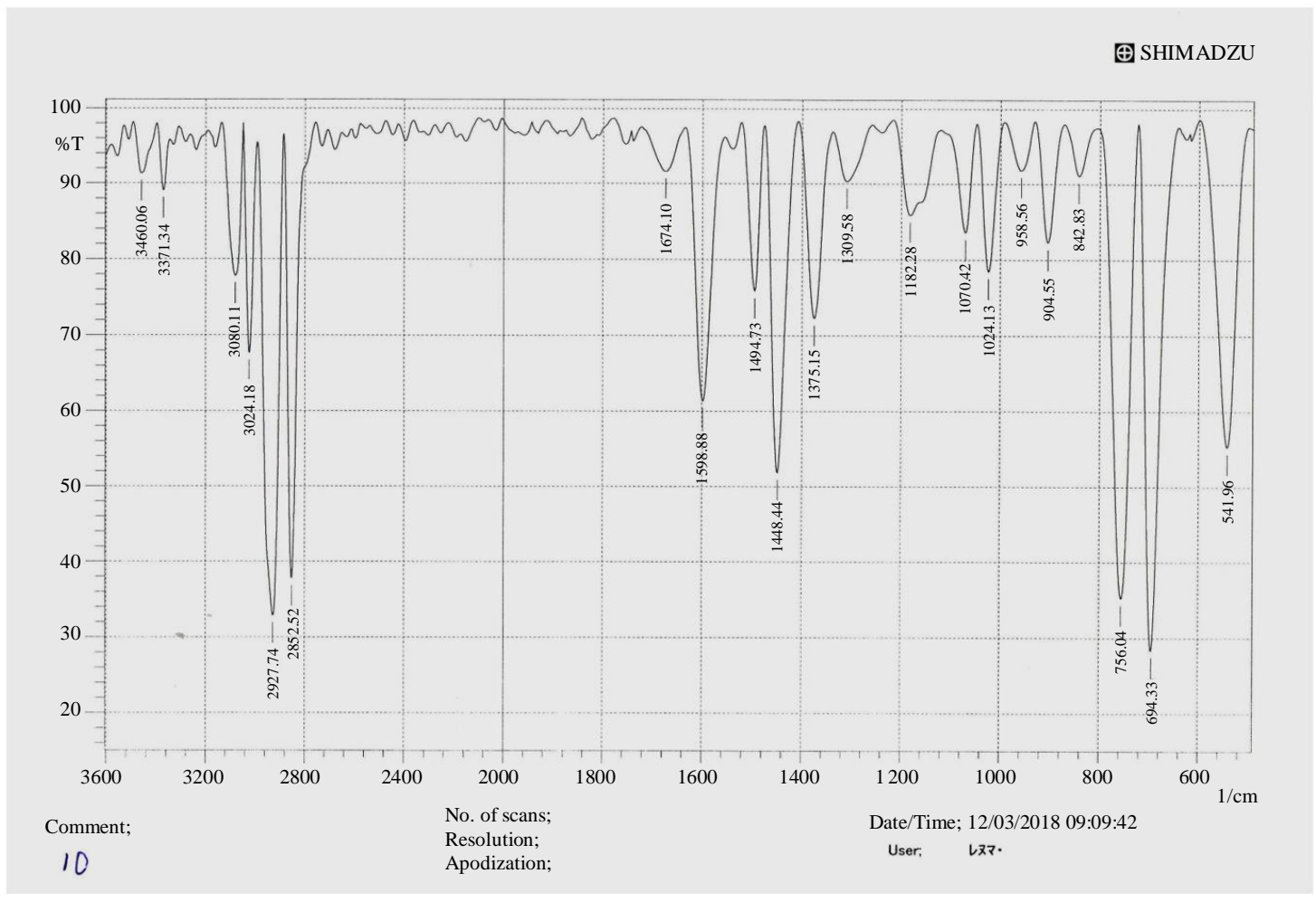

Fig. 1: FTIR spectra of pristine scrap tire sample

Table 1 and Fig. 2 of the decalin recovered rubber sample have shown almost the same Previous mentioned bands. Where the absorption frequencies at $1448 \mathrm{~cm}^{-1}$ and $1070 \mathrm{~cm}^{-1}$ represent $\gamma(\mathrm{C}=-\mathrm{C})$ aromatic ring and $\gamma(\mathrm{C}-\mathrm{H})$ in the plane, respectively, which are the main functional groups of the polystyrene present in the recovered rubber. The characteristic bands $\gamma(\mathrm{C}=\mathrm{C})$ of alkene and $\gamma(\mathrm{C}-\mathrm{H})_{\text {str }}$ of alkyl and alkenyl all belong to the butadiene moiety in the recovered rubber.

\section{$X$-Ray Diffraction Analysis}

The XRD pattern of pristine scrap tire Fig. 3 has shown that the examined material is non-crystalline with a very broad maxima $10^{\circ}$ to $20^{\circ}$ along $2 \theta$ axis, including some intense peaks. Those peaks belong to reinforcing filling inorganic materials and quantities of other additives (Chatterjee and Khobragade, 2017).

In general, the XRD pattern of the pristine scrap tire gives valuable information about the homogeneity of the sample which consist of different organic and inorganic materials mixed with rubber.

The X-ray diffraction of the recovered rubber shown in Fig. 4 has a broad maxima starts from $8^{\circ}$ to $24^{\circ}$ along $2 \theta$ axis which represents the SBR. The small maxima between $8^{\circ}$ to $12^{\circ}$ represents the polystyrene and that from $15^{\circ}$ to $24^{\circ}$ along the $2 \theta$ axis represents the polybutadiene in SBR (Essawy et al., 2012). While the sharp maxima peaks at $42^{\circ}, 44.8^{\circ}$ and $49^{\circ}$ represent the few organic additives present in the sample. 
๑ SHIMADZU

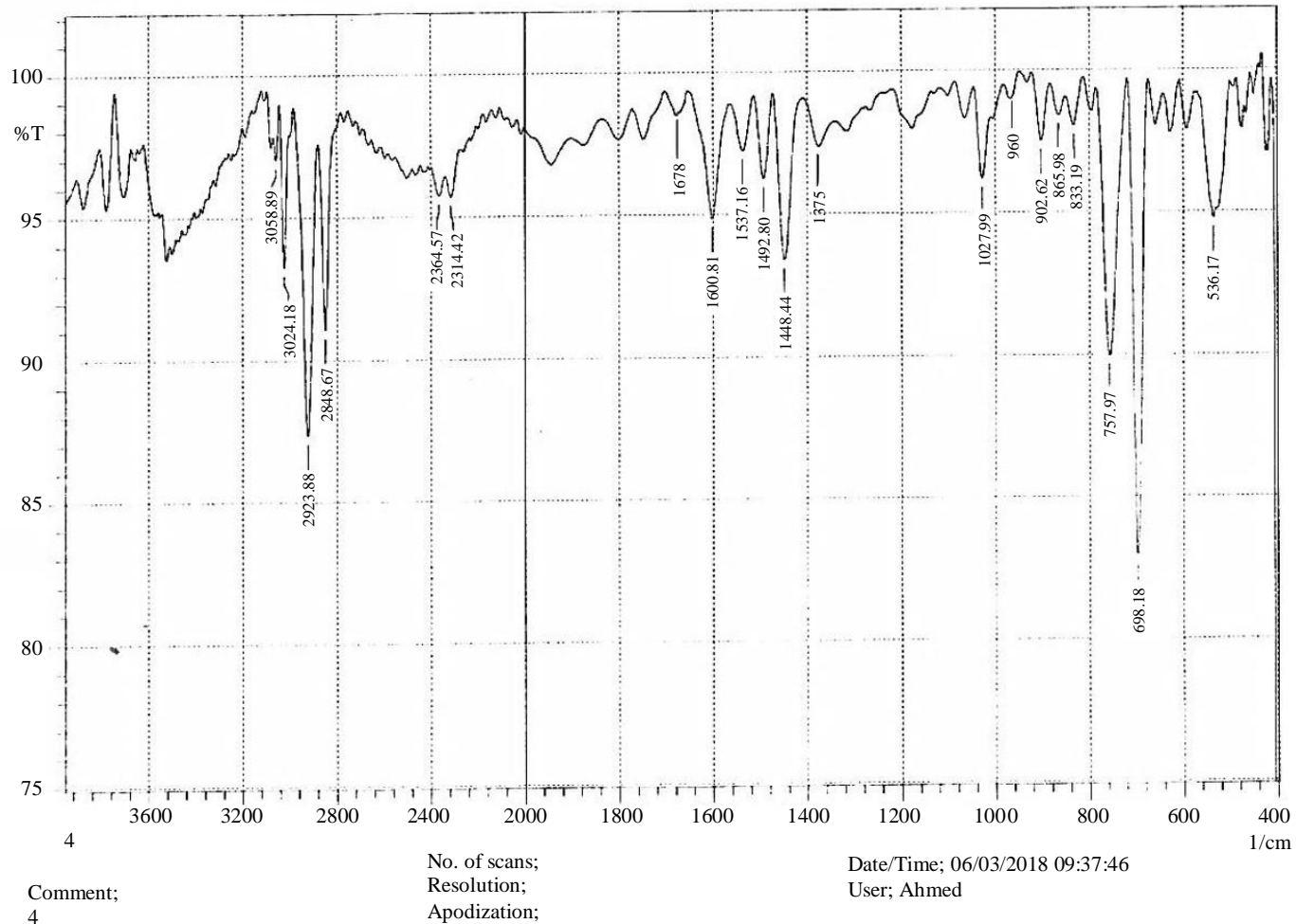

Fig. 2: FTIR spectra of recovered rubber from scrap tire sample treated with decalin

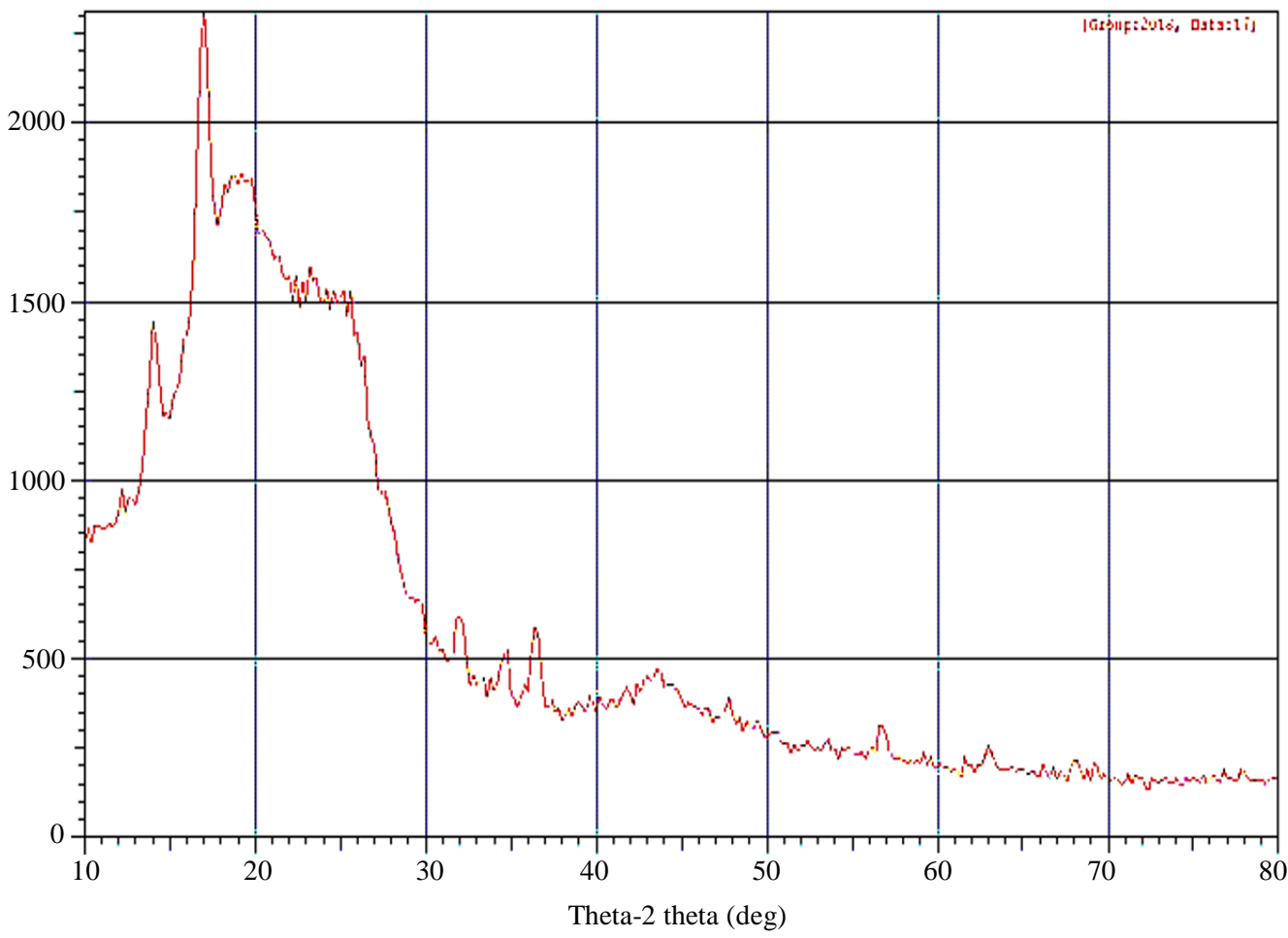

Fig. 3: XRD pattern of the scrap tire sample 


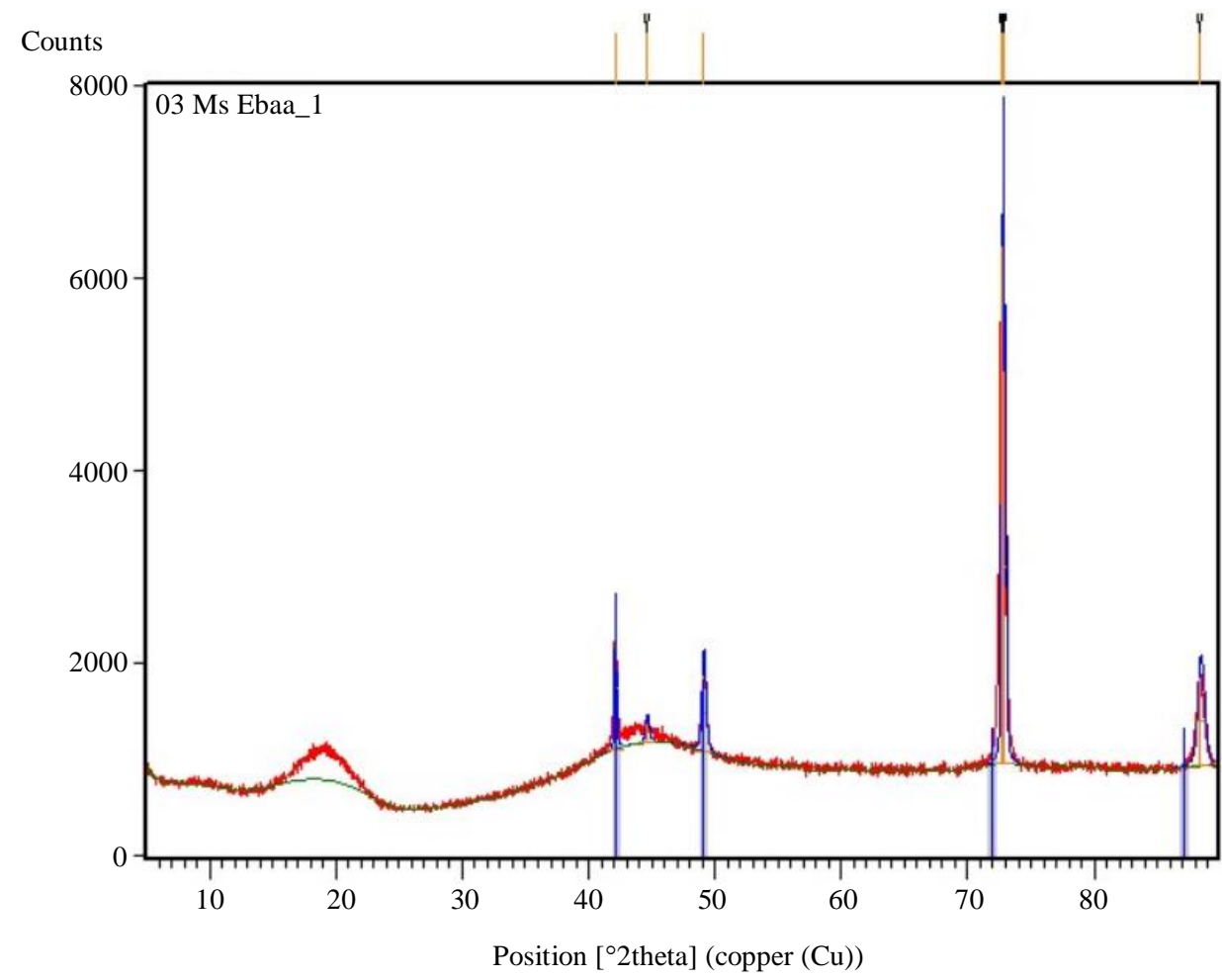

Fig. 4: XRD pattern of recovered rubber from scrap tire sample treated with decalin

Table 2: TG, DTG, DSC thermal parameters of decalin recovered rubber

\begin{tabular}{|c|c|c|c|c|c|c|}
\hline \multicolumn{3}{|c|}{ TG thermogram } & \multicolumn{2}{|l|}{ DTG thermogram } & \multicolumn{2}{|c|}{ DSC thermogram } \\
\hline $\begin{array}{l}\text { Thermal } \\
\text { parameter }\end{array}$ & $\begin{array}{l}\text { Weight } \\
\text { loss } \%\end{array}$ & Temp. ${ }^{\circ} \mathrm{C}$ & $\begin{array}{l}\text { Rate of decomp. } \\
(\mathrm{mg} \mathrm{min}-1)\end{array}$ & Temp. ${ }^{\circ} \mathrm{C}$ & $\mathrm{T}_{\mathrm{g}}{ }^{\circ} \mathrm{C}$ & $\begin{array}{l}\Delta \mathrm{H}_{\mathrm{f}} \\
\mathrm{J} . \mathrm{mg}^{-1}\end{array}$ \\
\hline IDT & 6.0 & 290 & 0.17 & 418 & $>0$ & +47.2 \\
\hline FDT & 100.0 & 450 & & & & \\
\hline $\mathrm{T}_{\max }$ & 47.0 & 405 & & & & -2.34 \\
\hline $\mathrm{T}_{\mathrm{cr}}$ & 98.5 & 435 & & & & \\
\hline
\end{tabular}

\section{Thermal Analysis}

TGA, DTG and DSC thermal analysis of the decalin recovered rubber were studied and their thermal parameters are displayed in Table 2. The TGA-thermogram in Fig. 5a shows the Initial Decomposition Temperature (IDT) of $6.0 \%$ weight loss at $290^{\circ} \mathrm{C}$ and $100 \%$ weight loss at the Final Decomposition Temperature (FDT) at $450^{\circ} \mathrm{C}$. The thermal parameters in Table 2 have shown that the decalin recovered material is thermally stable and its parameters are close to the parameters of styrenebutadiene rubber (Rybinski et al., 2013). The DTGthermogram Fig. 5b, Table 2 display the maximum rate of decomposition of decalin recovered rubber of $0.17 \mathrm{mg} \mathrm{min}^{-1}$ at $418^{\circ} \mathrm{C}$.
In general the rate of decomposition per minute is very low which means that the recovered rubber is thermally very stable (zhang et al., 2014).

The DSC-curve of the recovered rubber in Fig. 5 (c) records the heat of fusion $\Delta \mathrm{H}_{\mathrm{f}}$ of $+47.2 \mathrm{~J}_{\mathrm{mg}}{ }^{-1}$ with the appearance of a little magnitude of exothermic heat fusion of $-2.34 \mathrm{~J} . \mathrm{mg}^{-1}$ which may belong to the double bond decomposition of polybutadiene. Accordingly, the DSC- thermogram parameters give indications that the decalin recovered rubber is certainly styrene-butadiene rubber (Anyszka et al., 2016).

\section{SEM Analysis}

The SEM images of the pristine scrap tire sample in Fig. 6 show homogeneity of the tire components 
with some distributed cavities which look as black regions in the SEM image. The whitening spots distributed uniformly along the sample representing the carbon black filler. Moreover, the pristine scrap tire shows homogeneous sample present in elastic form and has molar cohesion which comes from the vulcanization process that gives the sample the visible folds, cavities and holes (Munteanu and Vasile, 2005).

The SEM image of decalin recovered rubber in Fig. 7 has shown a cohesive elastic surface containing folds and has large holes. The absence of whitening regions means the sample has no crystalline morphology and has rubbery texture.

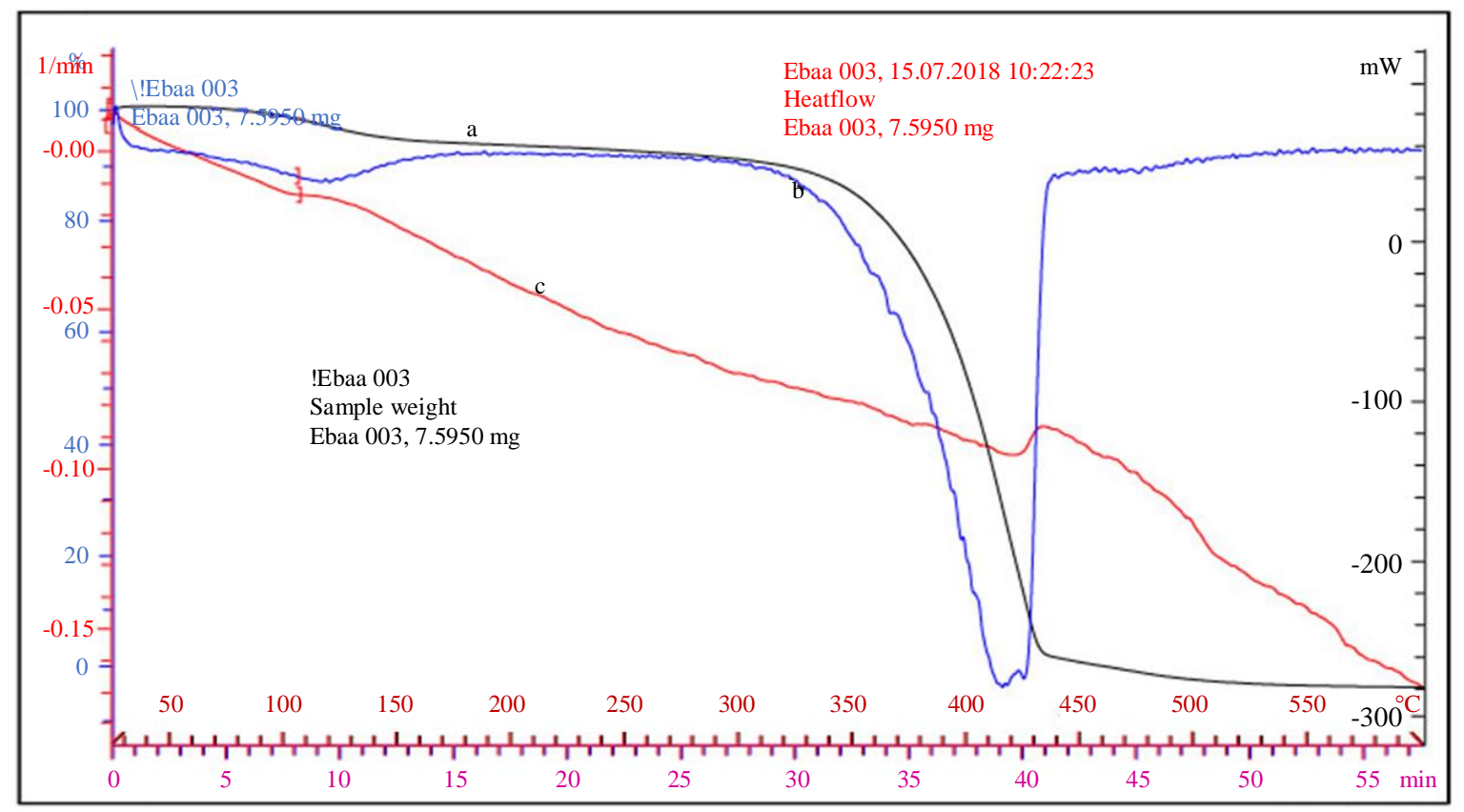

Fig. 5: (a) TGA (b) DTG (c) DSC thermogram of recovered rubber from the scrap tire sample extracted by decalin
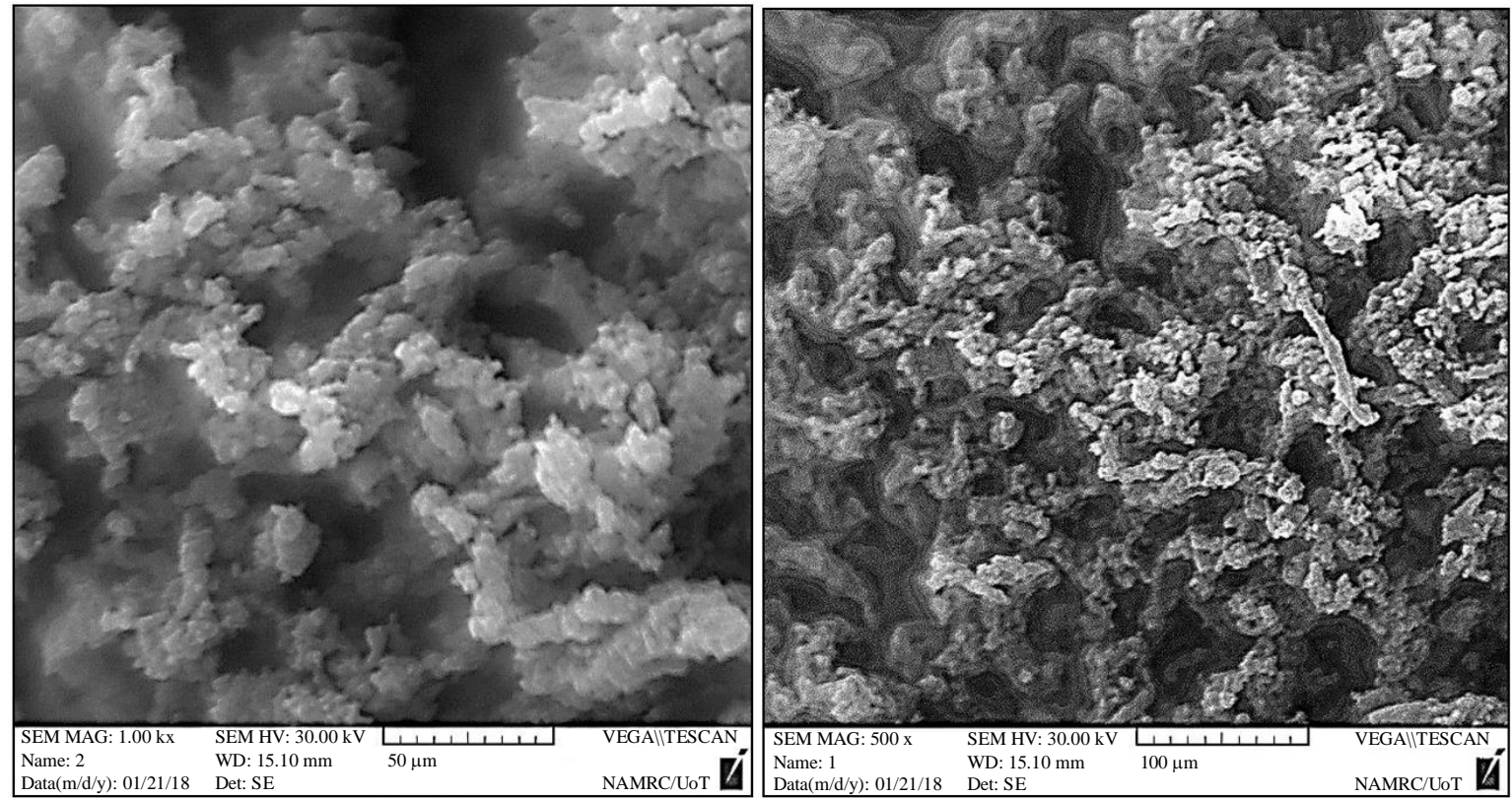

Fig. 6: SEM image of pristine scrap tire 


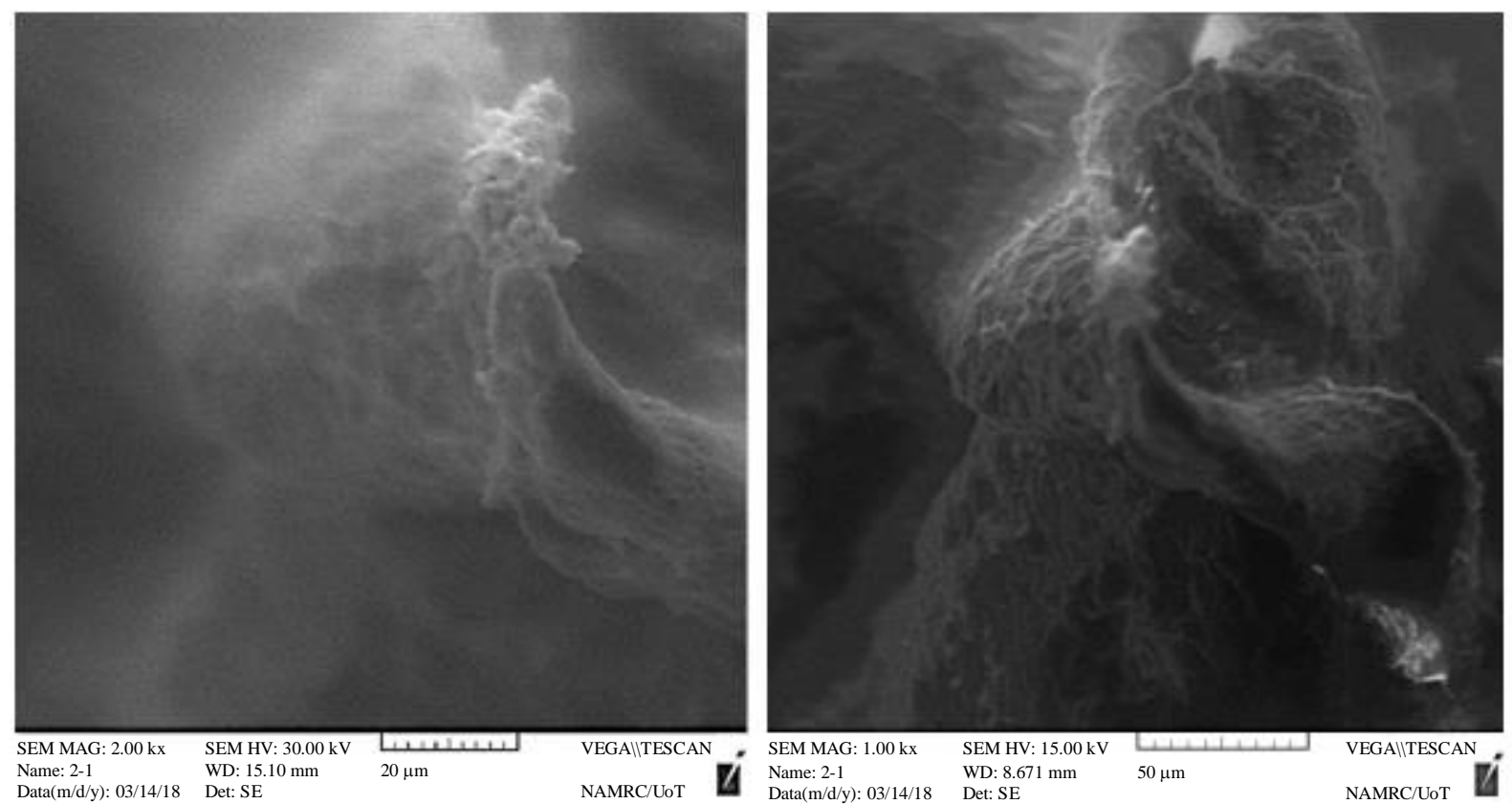

Fig. 7: SEM micrograph of the recovered rubber

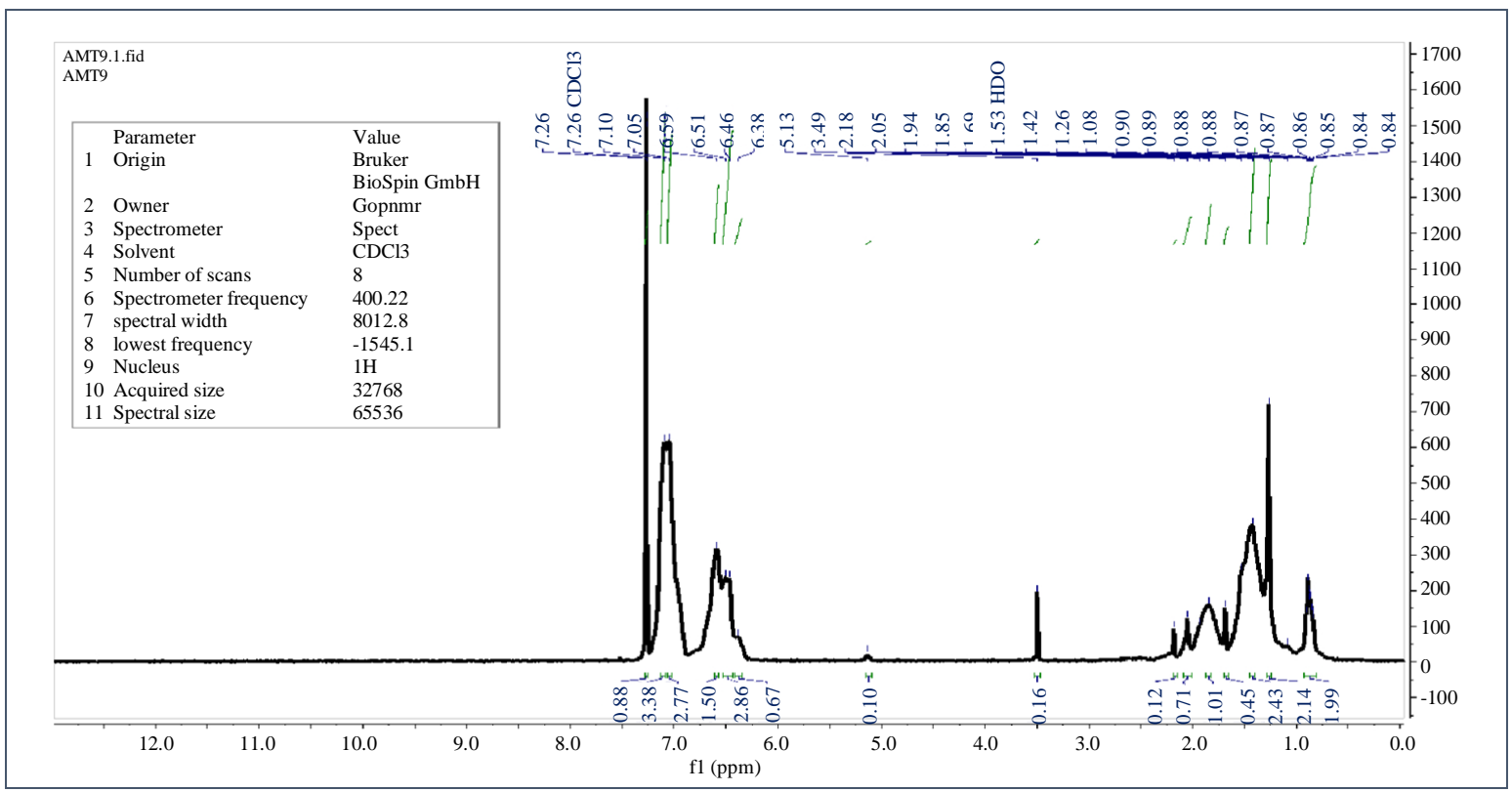

Fig. 8: ${ }^{1} \mathrm{HNMR}$ spectrum of recovered rubber from scrap tire extracted by decalin

\section{${ }^{1}$ HNMR Analysis}

The recovered rubber from grind scrap tire using decalin was examined by ${ }^{1} \mathrm{HNMR}$ analysis using $400 \mathrm{MHz}$, Bruker spectrometer and $\mathrm{CDCl}_{3}$ as deuterated solvent. The Fig. 8 has shown resonance of $(2 \mathrm{H}, \mathrm{m})$ at (3.49 and 5.13) $\mathrm{ppm}$ represent unsaturated ethylene group of the natural rubber.
Beside the resonance of $(2 \mathrm{H}, \mathrm{m})$ of methylene protons which belong to natural rubber. Styrene has shown resonance of $(5 \mathrm{H}, \mathrm{m})$ at $(7.05-7.26) \mathrm{ppm}$ represents aromatic protons of styrene ring. Finally, the compound have a resonance of $(5 \mathrm{H}, \mathrm{m})$ appeared at (6.38-6.59) $\mathrm{ppm}$ which represent aliphatic protons of styrene-butadiene main chain of the rubber. 


\section{Conclusion}

The final white recovered rubber which was extracted from scrap tires using decalin solvent was characterized with different sophisticated analysis in order to ascertain its composition.

The FTIR spectroscopy analysis show the main functional groups of the polystyrene $\gamma(\mathrm{C}=\mathrm{C})$ aromatic ring and $\gamma(\mathrm{C}-\mathrm{H})$ in the plane, beside $\gamma(\mathrm{C}=\mathrm{C})_{\text {str }}$ of the alkene belonging to polybutadiene rubber, thus indicating that the recovered rubber has styrenebutadiene rubber structure.

The XRD pattern of the recovered rubber show broad maxima which start from $8^{\circ}$ to $24^{\circ}$ on the $2 \theta$ axis is too much closer to the broad maxima of the non-crystalline styrene butadiene rubber. Moreover, the disappearance of peaks after $24^{\circ}$ means that decalin had extracted only rubber from the grind scrap tire and leaving the other additives. The thermal parameters of decalin recovered rubber give indication that the extracted material is thermally stable and its rate of decomposition is low and that its thermal parameters indicate that the material is styrene-butadiene rubber. The SEM image of the recovered material has shown morphological surface of rubber texture with cohesive elastic surface. The ${ }^{1} \mathrm{HNMR}$ has shown the final recovered rubber was SBR.

\section{Acknowledgment}

Authors are thankful for University of Mosul, Iraq for providing facilities to carry out this work. The first author would like to expand her greatest gratitude to all those who have directly or indirectly guided me to complete this work and in writing this paper especially Dr. Fawzi Habeeb Jabrail who guided me in my study.

\section{Author's Contributions}

Aeppa Mohammed Taher Sultan: Contributed in collection of literature and for carrying out experimental work.

Fawzi Habeeb Jabrail: Contributed in analysis, discussing and interpreting of the data. He also participated in writing and checking of final review of the draft.

\section{Ethics}

Both authors have read and approved the manuscript and there are no ethical issues associated with this research. This article is original and contains unpublished materials.

\section{References}

Aguado, J., D.P. Serrano, G. Vicente and N. Sanchez, 2006. Effect of decalin solvent on the thermal degradation of HDPE. Ind. Eng, Chem. Res., 14: 375-384. DOI: 10.1007/s10924-006-0034-3
Aguado, J., D.P. Serrano, G. Vicente and N. Sanchez, 2007. Enhanced production of $\alpha$-Olefins by Thermal Degradation of High-Density Polyethylene (HDPE) in Decalin solvent: Effect of the Reaction time and Temperature. Ind. Eng. Chem. Res., 46: 3497-3504. DOI: 10.1021/ie060975d

Anyszka, R., D. Bielinski, Z. Pedzich, P. Rybinski and M. Imiela et al., 2016. Thermal stability and flammability of Styrene-Butadiene Rubber (SBR) ceramifiable composites. Materials, 9: 604. DOI: $10.3390 / \mathrm{ma} 9070604$

Bryant J.T. and G.W. Burdette, 1978. High density liquid ramjet fuel. US Patent 4,099,931.

Chatterjee, A. and P.S. Khobragade, 2017. Rubber Nano Blends: Styrene-Butadiene Rubber Based Nanoblenda (SBR-nB): Preparation, Characterization and Applications. Springer Series on Polymer and Composite Materials (SSPCM). ISBN-10: 978-3-319-48718-2, pp: 209-248.

Czajczynska, D., R. Krzyzynska, H. Jouhara and N. Spencer, 2017. Use of pyrolytic gas from waste tire as a fuel. Energy, 134: 1121-1131. DOI: $10.1016 /$ j.energy.2017.05.042

Essawy, H.A., E. Tawfik and S.H. El-Sabbagh, 2012. Rubber Nanocomposites based on compatibilizer NBR/SBR blends using a series of amphiphilic montmorillonites. J. Elast. Plast., 46: 113-131. DOI: $10.1177 / 0095244312462162$

Leon-Bermudez, A.Y. and R. Salazar, 2008. Synthesis and characterization of the polystyrene-asphaltene graft copolymer by FT-IR spectroscopy. CT\&FCiencia Technol. Futuro, 3: 157-167.

Martinez, J.D., N. Puy, R. Murillo, T. Garcia and M.V. Navarro et al., 2013. Waste tire pyrolysis. Renew. Sust. Energ. Rev., 23: 179-213.

DOI: $10.1016 /$ j.rser.2013.02.038

Mastral, A.M., R. Murillo, M.S. Callen and T. Garcia, 1999. Application of coal conversion technology to tire processing. Fuel Proces. Tech., 60: 231-242. DOI: 10.1016/S0378-3820(99)00048-X

Mastral, A.M., R. Murillo, M.S. Callen, T. Garcia and C.E. Snape, 2000. Influence of process variables on oils from tire pyrolysis and hydro pyrolysis in a swept fixed bed reactor. Ener. Fuel, 14: 739-744. DOI: $10.1021 / \mathrm{ef} 990183 \mathrm{e}$

Munteanu, S.B. and C. Vasile, 2005. Special and thermal characterization of styrene-butadiene copolymers with different architectures. J. Optoelect. Adv. Mat., 7: 3135-3148.

Murugan, S., M.C. Ramaswamy and G. Nagarajar, 2009. Assessment of Pyrolysis oil as energy source for diesel Engines. Fuel Pro. Tech., 90: 67-74.

DOI: 10.1016/j.Fuproc.2008.07.017 
Aeppa M.T. Sultan and Fawzi Habeeb Jabrail / American Journal of Environmental Sciences 2019, 15 (4): 145.153 DOI: 10.3844/ajessp.2019.145.153

Rybinski, P., G. Janowska, M. Jozwiak and M. Jozwiak, 2013. Thermal stability and flammability of Styrene-Butadiene Rubber (SBR) Composites. J. Therm. Anal. Calari., 113: 43-52. DOI: $10.1007 / \mathrm{s} 10973-012-2871-8$

Umeki, E.R., C.F. de Oliveira, R.B. Torres, R.G. dos Santos, 2016. Physico-chemistry properties of fuel blends composed of diesel and tire pyrolysis oil. Fuel, 185: 236-242.

DOI: 10.1016/j.fuel.2016.07.092
Zhang, Y., Q. Zhang, Q. Liu, H. Cheng and R.L. Frost, 2014. Thermal stability of styrene composites filled with kaolinite/silica hybrid filler. J. Therm. Analy. Calari., 115: 1013-1020.

DOI: $10.1007 / \mathrm{s} 10973-013-3382-y$ 